\title{
Percepções maternas sobre o nascimento de um filho prematuro e cuidados após a alta
}

\author{
Maternal perceptions about the birth of a premature child and care after discharge
}

Percepciones maternas sobre el nacimiento de un hijo prematuro y cuidados después del alta

\author{
Lucy Sobieski dos Anjos', Daniela de Mattos Lemos', Letícia Alves Antunes", \\ João Marcus Oliveira Andrade', Weide Dayane Marques Nascimento"II, Antônio Prates Caldeira' ${ }^{\text {IV }}$ \\ ' Universidade Estadual de Montes Claros, Programa de Iniciação Científica. Montes Claros-MG, Brasil. \\ "Hospital Santa Casa de Montes Claros (Médica Residente). Montes Claros-MG, Brasil. \\ I"' Universidade Estadual de Montes Claros, Programa de Pós-Graduação em Ciências da Saúde (Mestranda). \\ Montes Claros-MG, Brasil. \\ "v Universidade Estadual de Montes Claros, Departamento de Saúde da Mulher e da Criança. Montes Claros-MG, Brasil.
}

\section{Submissão: 06-02-2011 Aprovação: 02-10-2012}

\section{RESUMO}

Estudo qualitativo que objetivou conhecer percepções maternas sobre o nascimento do filho prematuro e os cuidados após a alta. Os dados foram coletados por meio de entrevista semiestruturada com 16 mães de prematuros internados em UTIN, ou em acompanhamento pelo ambulatório de seguimento de recém-nascidos egressos de UTIN. As entrevistas foram gravadas, transcritas e interpretadas com base na Análise de Conteúdo. Os resultados revelaram sentimentos de tristeza, angústia, culpa e impotência. Registrou-se, ainda, confiança na equipe de saúde, insegurança com os cuidados ao filho em casa, a importância da rede de apoio social e da espiritualidade para as famílias. Profissionais que trabalham com prematuros devem dedicar maior atenção às suas famílias, compreendendo experiências críticas e acolhendo de forma humanizada.

Descritores: Nascimento Prematuro; Unidades de Terapia Intensiva Neonatal; Cuidado da Criança; Pesquisa Qualitativa.

\section{ABSTRACT}

This is a qualitative study, which aimed to identify maternal perceptions on premature birth and care of the newborn during hospitalization and after discharge. The data were collected through semi-structured interviews with 16 mothers of premature infants in NICU or in follow up ambulatory for infants discharged from NICU. The interviews were taped, transcribed and analyzed based on Content Analysis. Results revealed feelings of sadness, anguish, guilt and powerlessness. It was also reveled confidence in the health care team, uncertainty with the care of child at home, the importance of social network support and the role of spirituality for families. Professionals who work with infants should devote more attention to their families, understanding and accepting critical experiments in a humane way.

Key words: Premature Birth; Neonatal Intensive Care Units; Child Care; Qualitative Research.

\section{RESUMEN}

Investigación cualitativa con el objetivo de conocer la percepción materna sobre el nacimiento prematuro e el cuidado del recién-nacido durante la hospitalización e después del alta. Los datos fueron tomados mediante entrevista semi-estructurada a 16 madres con hijos prematuros internados en la UTIN o en la supervisión del seguimiento del ambulatorio para niños prematuros dados de alta de la UCIN. Las entrevistas fueron grabadas, transcritas y analizadas sobre la base de Análisis de Contenido. Los resultados revelaron sentimientos de tristeza, angustia, culpa e impotencia. Se registró también la confianza en el equipo de salud, la incertidumbre con el cuidado del niño en el hogar, la importancia de la red de apoyo social y de la espiritualidad para las familias. Los profesionales que trabajan con niños deben prestar más atención a sus familias, comprendiendo y aceptando los experimentos críticos de una manera humana.

Palabras clave: Nacimiento Prematuro; Unidades de Cuidado Intensivo Neonatal; Cuidado del Niño. Investigación Cualitativa. 


\section{INTRODUÇÃO}

O nascimento de um filho prematuro tem o potencial de produzir repercussões emocionais significativas para a mãe. Estudos revelam que as famílias e as mães, em particular, experimentem sentimentos ambivalentes em relação ao recém-nascido prematuro devido às suas condições de vulnerabilidade biológica ${ }^{(1-2)}$. Se por um lado existe a alegria pelo nascimento do filho, por outro lado também existem sentimentos de sofrimento, frustração e incompetência pela fragilidade do recém-nascido, que levam a significativas mudanças na dinâmica familiar ${ }^{(1-2)}$. Quando o filho prematuro permanece hospitalizado por longos períodos após o nascimento, ocorrem alterações no ritmo natural do nascimento, no funcionamento familiar e nos relacionamentos pessoais ${ }^{(2)}$.

Alguns estudos já apontaram que existe para as mães uma sobreposição de perdas, como a perda do filho idealizado e a impossibilidade de estar com o filho em casa. Agregam-se a essa sensação as cobranças familiares e sociais ${ }^{(3-4)}$. Não é raro que as mães desenvolvam, pois, neste momento sensações de fracasso, incapacidade e inferioridade. $\mathrm{O}$ nascimento de um filho prematuro efetivamente rompe com a construção da figura e da identidade materna. Muitas vezes, a interpretação do papel feminino passa a ser de desprezo, de inadequação. Em outras palavras, o nascimento prematuro tem o potencial de interferir negativamente com a autoestima da mulher, tanto em relação à sua capacidade maternal como em relação à sua feminilidade ${ }^{(4)}$.

O intenso sofrimento psíquico diante da prematuridade, que ameaça em alguns momentos a vida do filho, pode favorecer o surgimento de quadros depressivos, estados de ansiedade ou fobias. Esses sentimentos acompanham a mãe desde a admissão do seu filho em uma Unidade de Terapia Intensiva Neonatal (UTIN) e se estendem além da alta hospitalar ${ }^{(5-6)}$. Muitas vezes essa situação é desconhecida aos profissionais de saúde que lidam com os recém-nascidos nas UTIN ou em ambulatórios de seguimento. Para alguns autores, esses profissionais se apegam de forma demasiada ao saber técnico e acabam por negligenciar os aspectos psicossociais que envolvem a família ${ }^{(7-8)}$. Assim, faz-se necessário a compreensão apurada da temática, como instrumento subsidiador para ações de apoio às mães e às famílias nesse momento crítico.

Recém-nascidos prematuros trazem consigo o emblema da fragilidade, da necessidade de cuidados especiais e de mecanismos de proteção diferenciados. Assim, são naturais e desejáveis os questionamentos acerca da percepção materna sobre os cuidados com o seu filho prematuro, suas potencialidades e fraquezas para lidar com o filho imaturo. Outro aspecto desejável nesse momento é o estabelecimento de redes de apoio familiar e social, que são fundamentais para essas mães. Em algumas circunstâncias os ambulatórios de seguimento de recém-nascidos prematuros e egressos de UTIN representam importantes fontes de apoio e orientações para as mães e famílias de recém-nascidos prematuros. Especialmente porque, muitas vezes a permanência prolongada no hospital não é acompanhada por medidas de suporte às mães, nem mesmo para manutenção do aleitamento materno ${ }^{(9-10)}$.

As considerações apresentadas não são de cunho regional e mesmo autores internacionais recomendam que os profissionais envolvidos com os cuidados de recém-nascidos prematuros devam estar atentos também às necessidades dos pais para aliviar o estresse e os sentimentos de angústia que a família vivencia ${ }^{(11)}$. Nesse sentido, faz-se necessário que profissionais conheçam toda a ebulição de sentimentos que permeia o universo materno após o nascimento de um filho prematuro e compreendam a percepção das mães acerca do cuidado que seus filhos demandam nas UTIN e mesmo após a alta hospitalar, quando ainda são mais vulneráveis que as demais crianças. Nesse sentido, o presente estudo teve como objetivo conhecer percepções maternas sobre o nascimento do filho prematuro e os cuidados após a alta.

\section{MÉTODOS}

Trata-se de estudo descritivo e exploratório, de abordagem qualitativa, desenvolvido na UTIN e no Ambulatório de Follow-up do Hospital Santa Casa, no município de Montes Claros, Minas Gerais. O Hospital Santa Casa é considerado o maior hospital da região Norte de Minas Gerais, oferecendo atendimento público e privado em diversas especialidades médicas.

Os sujeitos compreenderam 18 mães, sendo oito de recém-nascidos prematuros ainda internados em UTIN e dez de crianças nascidas prematuramente e egressas de UTIN, em acompanhamento no ambulatório de seguimento (Ambulatório de Follow-up).

Os dados foram coletados por meio de entrevista semiestruturada, compreendida por seis questões norteadoras: 1) Fale sobre o sentimento diante do nascimento de um filho prematuro; 2) Quais os anseios e temores envolvidos na ocasião do parto? 3) Fale sobre sua percepção no cuidado ao filho prematuro; 4) Qual é a sua visão sobre a assistência prestada pela equipe de saúde ao filho prematuro? 5) Fale sobre os anseios e temores relacionados à alta hospitalar; 6) Fale sobre suas expectativas no cuidado domiciliar. Foi utilizado o critério de saturação como meio para definição do número de entrevistas ${ }^{(12)}$.

A análise ocorreu mediante as diretrizes de análise de conteúdo de Bardin ${ }^{(13)}$. Assim, na ordenação dos dados foram realizadas as transcrições das gravações, a releitura do material e a organização dos depoimentos. Após esta etapa procedeu-se a classificação dos dados onde houve a identificação das unidades de registro com uma numeração específica e o agrupamento dessas unidades em categorias ${ }^{(13)}$.

Todos os aspectos éticos foram respeitados durante a realização do estudo. Os participantes da pesquisa concordaram com a realização da mesma, mediante assinatura de termo de consentimento livre e esclarecido. O projeto foi aprovado pelo Comitê de Ética em Pesquisa da Universidade Estadual de Montes Claros (Unimontes) sob parecer nº 038/2010.

\section{RESULTADOS E DISCUSSÃO}

A análise dos dados permitiu o desvelamento de três categorias: sentimentos diante do nascimento de um filho prematuro; percepção do cuidado recebido e relação com a equipe de saúde; e as condições de cuidado após a alta. 
A. Sentimentos sobre o nascimento de um filho prematuro

Os sentimentos negativos representam uma das mais importantes e marcantes sensações vivenciadas pelas mães nos momentos iniciais. Os sujeitos relatam sentimentos de tristeza, desgosto, angústia e sofrimento como principais destaques diante do nascimento prematuro e da interrupção precoce da gestação.

... no inicio foi, assim, muito triste, eu ficava só chorando (MH1)

... eu sofri muito de ver ele lá e ter sido prematuro... O fato dele ser muito pequenininho, não podia levar ele pra casa... Então era muito sofrimento pra mim. (MA2)

... pra mim foi muito sofrido saber e ter um filho prematuro, fiquei muito triste e preocupada. Foi um sentimento de muita angústia. (MA5)

Percepções semelhantes foram relatadas por outros autores, que destacam que a internação de um filho em uma unidade de terapia intensiva é quase sempre um momento difícil para a família, que pode vivenciar sentimentos de incerteza quanto ao presente e futuro de seu familiar, sentimentos que envolvem as suas próprias perspectivas de vida ${ }^{(3-5)}$.

Tristeza e frustração são resultados e situações inesperadas e expectativas não alcançadas. As mulheres constroem, durante a gestação, um filho imaginário. Essa construção é gradual e inspira sonhos para a família. Esse processo implica na expectativa de filhos saudáveis e "prontos". A prematuridade e o ambiente das Unidades de Terapia Intensiva rompem com esses sonhos maternos e impõem às mães limitações à sua maternidade ${ }^{(7,14)}$.

Apesar do filho real, não é possível o abraço, o beijo e as carícias no colo. Não se permite à mulher ser uma mãe completa, já que até a idealização das funções maternas foi interrompida. As mães experimentam então os sentimentos vinculados à frustração e ao desalento de ser uma mãe incompleta. Destaca-se que, para essas mães, é negada a "festa social do nascimento", não havendo, pois um reconhecimento social da maternidade ${ }^{(14)}$.

Não é possível conceber que tais sentimentos estejam desagregados da percepção de fragilidade do filho recém-nascido. Segundo alguns autores, o prematuro é percebido como inacabado e frágil ${ }^{(1,14)}$. Para a mãe, essa fragilidade denota o risco de perda instantânea, o que pressupõe a angústia e a insegurança, conforme as falas a seguintes.

Ele nasceu com um quilo e setenta (gramas). Quando passou umas duas semanas depois eu perguntei quanto que ele estava pesando. Ele estava pesando novecentos e poucas (gramas). Eu pensei: agora que ele não vai viver mesmo... (MH4).

Eu senti, assim, uma espécie de... uma insegurança, sabe? Porque eu tenho a impressão, assim, que CTI é a antessala do cemitério, não é? Dá aquele medo ali... (MA3).
Menino prematuro é muito sensível. Vai ter que ter um tempo só pra ele, não vai poder chorar muito, que menino prematuro os órgãos não estão bem constituídos ainda. (MH5).

Eu senti muito, muito mal, assim, achando que ele não ia sobreviver, só isso. Cheguei lá e na hora que eu vi eu assustei que ele era muito pequenininho (MH6).

Na linguagem das mães é possível perceber que a fragilidade biológica dos filhos prematuros imprime a sensação de morte iminente, o que também é uma situação estressante e ansiogênica. Outros autores descrevem que essa situação leva as mães a viverem um "aparente estado de luto"(3).

\section{Sensação de impotência}

Diante do fenômeno discutido, a sensação de impotência representou outro aspecto salientado pelas mães.

Eu chegava ali, eu ficava torcendo para que aquilo ali passasse logo e via as experiências das outras mães que tanto tempo estavam ali e ficava perguntando pra mim: será quanto tempo você vai ficar aqui? (MA3).

Tem dia que você chega tem uma notícia muito boa, aí tem dia que você chega tem uma razoável, tem dia que você chega que não tem uma (notícia) tão boa. Aí você vai pra casa chorando...Ah, é difícil demais ver aquilo (MH3).

Aceitar, às vezes agente aceita não é porque quer, é porque é o jeito. (MH8).

Se pudesse voltaria, com ele para barriga... (silêncio e lágrimas)... Se pudesse fazer uma coisa dessa... você tem um filho muito frágil, como se você pudesse fazer alguma coisa e ao mesmo tempo você não pode fazer nada (MH6).

Esse aspecto já foi apontado por outros autores ${ }^{(4)}$, que destacam ainda que além do desapontamento, o nascimento de um filho prematuro produz um sentimento de incapacidade para as mães. Essa percepção é mais notável para os momentos vivenciados durante a passagem do filho pela UTIN ${ }^{(15)}$.

O ambiente da UTIN é estranho para a maioria das pessoas que não atuam nele. Não se trata de mais uma enfermaria pediátrica, mas de um centro de grande densidade tecnológica, onde o cuidar biológico está atrelado à utilização de máquinas e equipamentos desconhecidos para a maioria dos leigos. As visitas das mães às UTIN são impactantes não apenas pela visão do filho prematuro, mas também pelo desconcertante ambiente, onde elas não sabem como se comportar, o que podem ou não fazer. Muitas não ousam tocar o filho com receio de comprometer a dinâmica dos equipamentos a ele ligados. Também essa situação consolida para as mães a sensação de impotência.

Em algumas situações, durante uma gestação sabidamente de risco, as mães podem ter suas angústias antecipadas e trabalhadas sob o aspecto psicológico. Entretanto, quase sempre o nascimento de um filho é um evento social festivo. Sua antecipação, 
especialmente, quando vinculada ao risco de morte da criança recém-nascida, é sempre uma situação inesperada.

Em outras circunstâncias, não existe sequer o pensamento sobre a possibilidade do nascimento prematuro, isto é, a prematuridade emerge de um contexto absolutamente inesperado para as mães, que se sentem completamente perdidas. Esse é um fato que exacerba a sensação de impotência e que pode desestabilizar algumas mães, conforme os discursos seguintes:

Eu levei um susto, eu entrei em desespero, eu não queria mais vir aqui... (MH1)

Foi de repente e eu não esperava. O médico falou que tinha que nascer ou então ele ia morrer... Nem sei o que me deu na hora, que eu não lembro de nada. De uma hora para outra eu já estava aqui visitando ele, todo cheio de aparelho e eu não podia fazer nada. Dá uma sensação muito ruim... (MH8).

\section{Sentimentos de culpa}

Segundo Fraga e Pedro, o sentimento de culpa diante do nascimento de rum filho prematuro origina-se da necessidade humana de racionalizar ou encontrar causas racionais para o fato $^{(5)}$. Alguns registros da escuta realizada neste estudo mostraram que a sensação de culpa também permeia o universo das mães entrevistadas.

"Eu fico sentindo que foi minha culpa. Você carrega aquela culpa para o resto da vida... Culpa de, por exemplo, ver o filho recebendo agulhada, tirando sangue, sofrendo ali e eu não poder fazer nada." (MH5).

A gente se sente culpada de não ter feito as coisas certas. Eu... não deu para ir no pré-natal e se eu tivesse ido, talvez ele ainda 'estava' aqui na barriga (MH7).

Realmente a gente se sente culpada por isso. Eu sempre mim pergunto o que eu fiz de errado pra que meu filho nascesse assim (MA7).

...quando eu ia dormir ou quando chegava pra ver meu filho e olhava pra ele naquela situação, me perguntava se a culpa era minha (MH2)

Essa percepção de culpa seguramente acentua os sentimentos negativos da mãe em relação ao momento em que está vivendo. Diante da interrupção precoce de uma gestação é desejável que a equipe de saúde desconstrua essa percepção entre as mães. Para alguns autores, todos esses sentimentos negativos vivenciados em conjunto com o sentimento de culpa e impotência exacerbam o medo real de perder o filho recém-nascido e podem comprometer a afetividade entre pais e filhos ${ }^{(1,14)}$.

\section{B. Percepção sobre os cuidados recebidos e a relação com a equipe de saúde}

A sobrevida de recém-nascidos prematuros e de muito baixo peso já não representa uma situação anômala e ocasional.
A tecnologia utilizada nas UTIN tem conseguido significativo sucesso para crianças que até alguns anos atrás não alcançariam sobrevida. Com esses resultados as equipes de saúde em terapia intensiva têm sido solicitadas a se voltarem também para as famílias dos prematuros. O novo desafio não é apenas prover o melhor cuidado disponível para os recém-nascidos prematuros, mas também auxiliar as mães no processo de compreensão do momento e dos sentimentos acerca de sua maternidade ${ }^{(16-18)}$.

É importante, pois, que os profissionais de saúde percebam todo turbilhão de sentimentos que permeiam as atitudes das mães e familiares e que trabalhem na perspectiva de aliviar as situações estressantes. Quando os profissionais reconhecem esse momento crítico das mães, suas atitudes podem agir terapeuticamente sobre a família(19)

Para as mães participantes desta pesquisa registrou-se uma percepção positiva sobre a equipe da UTIN e do ambulatório de seguimento, com discursos que denotam sensação de amparo por parte dos profissionais.

Eles todos são muito bons, eles cuidam direitinho, a gente fica até mais aliviada...(MH2).

Todos eles tratam a gente, assim, super bem, explica pra gente como é que está sendo o tratamento dela... a assistência é muito boa (MH1).

Eles têm a melhor maneira de me dar resposta sem me ferir, porque tem umas (pessoas) que chegam, já vão dando respostas com brutalidade... Tem que ter paciência. Achei muito bom os cuidados daqui ( $\mathrm{MH} 5$ )

Algumas mães chegam a expressar literalmente o quanto os profissionais de saúde influenciaram em aliviar a ansiedade e promover sentimentos de esperança e otimismo:

Qualquer médico que tenha um pouquinho de humanidade, ele conversa, ele fala e te dá esperança, ele te ajuda a enfrentar a situação com as palavras dele, uma palavra amiga... (MA6).

O que eles tentaram salvar, salvaram a minha vida como mãe e a vida do meu filho (MH6).

Tem certas horas que o necessário é simplesmente uma palavra amiga mesmo, de uma pessoa positiva e o que eles tentam fazer é isso, ser positivos com você, dar força, para você não ficar rendida ao terror, àquela coisa ruim, ao sofrimento (MH5).

As enfermeiras ajudam muito, apoiava, explicava as coisas e acalmava, porque eu chorava muito. Quanto eu chegava no hospital sempre tinha alguém pra me acalmar (MA5).

Os relatos deixam claro que as famílias apresentam demandas específicas de cuidado além do amparo tecnológico ao fiIho recém-nascido. As mães expressam de forma transparente 
que o conforto recebido dos profissionais de saúde é parte inerente do tratamento, uma extensão natural do cuidado do filho à família. Isso é registrado pelas famílias através das explicações, do acolhimento e do apoio nos momentos mais críticos do tratamento. Outros trabalhos já destacaram esse aspecto, pontuando que muitas mães de crianças prematuras superam seus medos a partir de uma maior interação com os profissionais de saúde ${ }^{(1,20)}$. Depreende-se de tais considerações que a comunicação e as relações interpessoais com as famílias de recém-nascidos prematuros devem ser tão valorizadas quanto o cuidado tecnológico nas UTIN ${ }^{(1,11,19-20)}$.

\section{Perspectivas de cuidados com o recém-nascido prema- turo em casa}

Na presente categoria três subcategorias foram desveladas: a) insegurança no cuidados com o filho prematuro; b) necessidade de apoio familiar e; c) força na espiritualidade.

\section{Insegurança no cuidados com o filho prematuro}

Vieira e Melo lembram que, apesar da alta hospitalar ser um dos momentos mais desejados pela família de crianças prematuras, existe a ansiedade e insegurança acerca do cuidar em domicílio, sem a presença da equipe de saúde ${ }^{(16)}$. Nas entrevistas com as mães que ainda estavam em acompanhamento nas UTIN o receio de cuidar do filho prematuro foi salientado de forma mais destacada.

Só que eu tenho muito medo. Medo de não saber cuidar direito e de machucar ela (MH1).

Eu tenho que dar conta, mas eu tenho medo de não ser uma mãe já preparada (MH8).

Ele deve pedir um bocado de exigência... Deve ser desse jeito. Deve ser difícil no começo (MH4).

Aí se eu tiver fazendo alguma coisa, se ela começar a chorar eu vou ter que largar tudo para cuidar dela (MH5).

A percepção de que o filho prematuro demanda cuidados redobrados não é irreal. Existe, por exemplo, a demanda de maior atenção aos cuidados alimentares pelo risco de aspiração e refluxo gastroesofágico, mais comuns nesse grupo de crianças. O próprio manuseio da criança nas primeiras semanas é mais delicado devido a sua natural hipotonia muscular. Muitas crianças recebem alta em uso de vários medicamentos, fato que também implica em maior atenção e dedicação por parte dos cuidadores. A literatura registra que, mesmo as mães que receberam orientações ao longo da internação dos filhos, sentem-se inseguras e com dificuldades nos momentos iniciais ${ }^{(21)}$.

\section{Necessidade do apoio familiar}

A construção de redes intrafamiliares de apoio é fundamental para assegurar às mães maior segurança e tranqüilidade nos momentos mais difíceis. Esse aspecto foi apontado pelas mães cujos filhos ainda estavam nas UTIN e corroboradas pelas mães cujos filhos estavam em acompanhamento ambulatorial.
Acho que eu vou precisar muito de minha mãe em casa; de uma boa madrinha, das vizinhas (MH7).

Tem minha avó e tem minha tia que moram lá também, então, assim, lá em casa, o que mais tem é gente pra cuidar, então eu não preocupo com isso (MH1).

Minha mãe me ajudou. Minha mãe me ajudou muito e, assim, ela me explicou o jeito de pegar... como é que eu ia segurar para dar banho...Tudo! Aí lá foi mais tranqüilo (...) Porque também em casa, com as pessoas orientando e olhando é mais fácil (MA10).

Efetivamente, muitas mães sentem-se inseguras em relação aos cuidados iniciais com os filhos prematuros em casa ${ }^{(21)}$. Algumas registram esse aspecto de forma bem objetiva, conforme os relatos seguintes:

Achei que o banho, a mamadeira, que qualquer coisinha já era uma coisa de outro mundo... Em casa não tinha segurança nenhuma (para) dar o banho, a mamadeira... Tinha medo (MA9)

Achei que não ia conseguir dar o remédio, que eu tinha medo de dar o remédio e ele engasgar... Até para pegar eu achava que eu ia machucar ele e para dá o banho... Tudo eu sentia insegurança (MA3)

Eu tinha muito medo e insegurança na hora do banho e de trocar. Achava que meu filho ia 'quebrar'. Ficava como muito medo, meu Deus (MA1)

Frequentemente, os profissionais de saúde que atuam nos hospitais não indagam sobre a rede de apoio familiar e não estimulam a construção de apoio para o cuidado com a criança prematura no domicílio. Nesse sentido, o Ambulatório de Seguimento representa um importante apoio para as famílias. A assistência multiprofissional naturalmente agrega informações sobre o cuidado em casa. É desejável que a integração da rede de apoio busque integrar os saberes da família, dos vizinhos e da comunidade em geral, valorizando aspectos positivos das informações colhidas. Assim ele promove um cuidado real e tem oportunidade de adequar comportamentos equivocados, respeitando valores culturais, convicções e expectativas da família e da comunidade ${ }^{(16)}$.

Vários autores destacam a importância da rede social para amparar as mães de crianças prematuras ${ }^{(6,16,21)}$. Existe para essas famílias uma situação real que inspira receios diversos: o cuidar do recém-nascido frágil. A troca de experiências, o compartilhamento de dificuldades pode, de fato, propiciar para essas mães o aflorar de sentimentos mais positivos à sua maternidade fragilizada.

\section{Força na espiritualidade}

No presente estudo as mães destacaram o papel da espiritualidade no conforto à estressante situação que experimentavam: 
No outro dia a gente chegou lá, ela já estava tudo normal. Graças a Deus! Eu peço muito a Deus, que se for um caso de vir a acontecer pra 'mim' estar preparada. Porque é muito difícil...(MA10).

Assim, não só o meu bebê, mas tem vários bebês lá e é uma lição de vida que agente tem. Agente pode dizer que é uma lição, porque você tem que ter fé, força e muita, é, assim, muita fé (MA4).

Eu chorava pedindo a Deus para cuidar dele, que eu tive muito medo de perder ele, muito medo. (...) assim, que Deus já tinha preparado para mim, sabe, assim, Deus já tinha me mostrado que tudo ia dá certo. Deus é maravilhoso que deu tudo certinho (MA8).

A necessidade de adaptação da mãe e da família à difícil condição instalada pelo nascimento de um filho prematuro sofre influência de diversos fatores. Embora o vínculo com os aspectos espirituais sejam raramente e superficialmente apontados em estudos semelhantes, é compreensível que essa dimensão esteja presente para muitas mães, especialmente em um país de grande religiosidade, como o Brasil. A expressão "Graças a Deus" permeou o discurso de 16 entre as 18 mães entrevistadas. É compreensível que diante dos sentimentos de insegurança, culpa e tristeza vivenciados, as crenças e práticas religiosas sejam importantes auxiliares para o enfrentamento e dos questionamentos, quase sempre não explícitos, sobre o viver e o morrer.

Em um estudo com familiares de crianças gravemente enfermas, destacou-se que essas famílias buscam através da fé atribuir significados às experiências vividas e expressam, através de suas crenças religiosas a esperança de resultados positivos $^{(22)}$. A necessidade de que o profissional de saúde, e particularmente o enfermeiro, esteja receptivo e compreensível a esse olhar já foi apontado em outros aspectos do cuidar pediátrico, em crianças com câncer $^{(23)}$ e em crianças com insuficiência renal crônica ${ }^{(24)}$. É importante que também os profissionais que lidam com as famílias de recém-nascidos prematuros compreendam o papel da religião e da espiritualidade da família no processo de cuidar e tenham atitudes acolhedoras e desprovidas de preconceitos.

\section{CONSIDERAÇÕES FINAIS}

O nascimento de um filho prematuro representa uma experiência crítica para mães e familiares e deve merecer, por parte das equipes de saúde, máximo zelo possível com maximização dos cuidados destinados à recuperação da saúde do bebê, mas também com valorização dos cuidados à família fragilizada. Os resultados e análises registrados neste estudo podem fornecer importantes subsídios para a mudança de práticas e melhor compreensão dos sentimentos maternos em serviços de terapia intensiva, maternidades e ambulatórios de seguimento para recém-nascidos prematuros ou de baixo peso.

\section{REFERÊECIAS}

1. Tronchin DMR, Tsunechiro MA. A experiência de tornarem-se pais de prematuros um enfoque etnográfico. Rev Bras Enferm 2005;58(1):49-54.

2. Vasconcelos MGL, Leite AM, Scochi CGS. Significados atribuídos à vivência materna como acompanhante do recém-nascido pré-termo e de baixo peso. Rev Bras Saúde Matern Infant 2006;6:47-57.

3. Sales AC, Alves NB, Vrecchi MR, Fernandes J. Concepções das mães sobre os filhos prematuros em UTI. Rev Bras Enferm 2006;59:20-4.

4. Arruda DC, Marcon SS. A família em expansão: experienciando intercorrências na gestação e no parto do bebê prematuro com muito baixo peso. Texto \& Contexto Enferm 2007;16:120-8.

5. Fraga ITG, Pedro ENR. Sentimentos das mães de recém-nascidos prematuros: implicações para a enfermagem. Rev Gaúch Enferm 2004;25:89-97.

6. Bengozi TM, Souza SNDH, Rosseto EG, Radigonda B, Hayakawa LM, Ramalho DP. Uma rede de apoio à família do prematuro. Ciênc Cuid Saúde 2010;9:155-60.

7. Raad AJ, Cruz AMC, Nascimento MA. A realidade das mães numa unidade de terapia intensiva neonatal. Rev Psicol Vetor Ed [periódico na internet]. 2006 [acesso em 23 maio 2009]:17(2) Disponível em: < http:// pepsic.bvs-psi.org.br $>$.
8. Pêgo JA, Maia S, Suzana M. A importância do ambiente no desenvolvimento do recém-nascido pré-termo. Distúrb comun 2007; 19:39-50.

9. Braga DF, Machado MMT, Bossi MLM. Amamentação exclusiva de recém-nascidos prematuros: percepções e experiências de lactantes usuárias de um serviço público especializado. Rev Nutr 2008; 21:293-302.

10. Serra SOA, Scochi CGS. Dificuldades maternas no processo de aleitamento materno de prematuros em uma UTI neonatal. Rev Latino-Am Enferm 2004;12:597-605.

11. Aagaard $\mathrm{H}$; Hall EO. Mothers' experiences of having a preterm infant in the neonatal care unit: a meta-synthesis. J Pediatr Nurs 2008;23:26-36.

12. Minayo MCS. O desafio do conhecimento: pesquisa qualitativa em saúde. 11. ed. São Paulo: HUCITEC; ABRASCO; 2008.

13. Bardin L. Análise de conteúdo. Lisboa: Edição 70; 2008.

14. Marson AP. Narcisismo materno: quando meu bebê não vai para casa.... Rev SBPH [periódico na internet]. 2008 [acesso em 30 maio 2009];11(1) Disponível em: < http:// pepsic.bvs-psi.org.br/pdf $>$.

15. Cruz ARM, Oliveira MMC, Cardoso MVLML, Lúcio IML. Sentimentos e expectativas da mãe com filho prematuro em ventilação mecânica. Rev Eletrônica Enferm [periódico 
na internet]. 2010 [acesso em 20 maio 2010];12:133-9 Disponível em: <http://www.fen.ufg.br/revista/v12/n1/ v12n1a16.htm >

16. Vieira CS, Mello DF. O seguimento da saúde da criança pré-termo e de baixo peso egressa da terapia intensiva neonatal. Texto \& Contexto Enferm 2009;18:74-82.

17. Reichert APS, Lins RNP, Collet N. Humanização do cuidado da UTIN. Rev Eletrônica Enferm [ periódico na internet]. 2007 [acesso em 27 maio 2009];9:200-13 Disponível em: <http://www.fen.ufg.br/revista/v9/n1/pdf/ v9n1a16.pdf $>$

18. Fraga TF, Amante LN, Anders JC, Padilha MICS, Henckemaeir L, Costa R, Bock LF. Percepção das mães sobre o processo comunicacional na unidade de terapia intensiva neonatal. Rev Eletrônica Enferm [ periódico na internet]. 2009 [acesso em 20 maio 2010];11(3):612-9 Disponível em: < http://www.fen.ufg.br/revista/v11/n3/v11n3a19.htm >

19. Simioni AS, Geib LTC. Percepção materna quanto ao apoio social recebido no cuidado às crianças prematuras no domicílio. Rev Bras Enferm 2008;61:654-1.

20. Silva RV, Silva IA. A vivência de mães de recém-nascidos prematuros no processo de lactação e amamentação. Esc Anna Nery Rev Enferm 2009;13:108-15.

21. Soares DC, Cecagno D, Milbrath VM, Oliveira NA, Cecagno S, Siqueira $\mathrm{HCH}$. Faces do cuidado ao prematuro extremo no domicílio. Ciênc Cuid Saúde 2010;9:238-45.

22. Bousso RS, Serafim TS, Misko MD. The relationship between religion, illness and death in life histories of family members of children with life-threatening diseases. Rev Latino-Am Enferm 2010;18:156-62.

23. Nascimento LC, Oliveira FCS, Moreno MF, Silva FM. Cuidado espiritual: componente essencial da prática da enfermeira pediátrica na oncologia. Acta Paul Enferm 2010;23:437-40.

24. Paula ES, Nascimento LC, Rocha, SMM. Religião e espiritualidade: experiência de famílias de crianças com Insuficiência Renal Crônica. Rev Bras Enferm 2009;62:100-6. 